\title{
The "graying" of infertility services: an impending revolution nobody is ready for
}

\author{
Norbert Gleicher ${ }^{1,2^{*}}$, Vitaly A Kushnir ${ }^{1}$, Andrea Weghofer ${ }^{1,3}$ and David H Barad ${ }^{1,2}$
}

\begin{abstract}
Background: As demand for infertility services by older women continues to grow, because achievable in vitro fertilization (IVF) outcomes are widely underestimated, most fertility centers do not offer maximal treatment options with use of autologous oocytes. Limited data suggest that clinical IVF outcomes in excess of what the American Society for Reproductive Medicine (ASRM) considers "futile" can, likely, be achieved up to at least age 45 years.

Methods: In an attempt to point out an evolving demographic trend in IVF, we here report our center's IVF data for 2010-2012 and national U.S. data for 1997-2010. Though our center's data are representative of only one IVF center's patients, they, likely, are unique since they probably represent the most adversely selected IVF patient population ever reported and, thus, are predictive of future demographic trends. In addition we performed a systematic review of the literature on the subject based on PubMed, Medline and Google Scholar searches till year-end 2013. The literature search was performed using key words and phrases relevant to fertility treatments in older women.
\end{abstract}

Results: As demonstrated by our center's patient demographics and national U.S. data, IVF centers are destined to treat increasingly adversely selected patients. Despite our center's already extremely adversely selected patient population, age-specific IVF cycle outcomes in women above age 40 years, nevertheless, exceeded criteria for "futility" by the ASRM and widely quoted outcome expectations in the literature for patient ages. Age 43 discriminates between better and poorer clinical pregnancy and live birth rates.

Conclusions: "Graying" of the infertility populations in the developed world, a problem with potentially far-reaching medical and societal consequences, has so far been only insufficiently addressed in the literature. As women's postmenopausal life spans already exceed postmenarcheal life spans at the start of the $20^{\text {th }}$ century, the "graying" of infertility services can be expected to further accelerate, no longer as in recent decades bringing only women in their 40s into maternity wards but also women in their 50s and 60s. Medicine and society better get ready for this revolution.

Keywords: Infertility, Advanced age, Infertility treatments, Age limitations, Clinical consequences, Societal consequences

\section{Background}

Women above age 40 in the United States (U.S.) now represent the proportionally fastest growing age group having children [1,2]. Potential medical and societal consequences have found little attention in the medical literature, even though a recent study once again offered convincing evidence for the importance of age as a predictor of failure to achieve live birth [3].

\footnotetext{
* Correspondence: ngleicher@thechr.com

${ }^{1}$ Center for Human Reproduction, New York, NY 10021, USA

${ }^{2}$ Foundation for Reproductive Medicine, New York, NY 10021, USA

Full list of author information is available at the end of the article
}

Because favorable patients now usually conceive relatively quickly with in vitro fertilization (IVF), unfavorable patients accumulate disproportionally in IVF centers. This trend is further aggravated by above noted new reality in the U.S. that older and older women are trying to conceive.

Since our center for at least five years has been serving primarily as a "center of last resort" for patients who previously have failed IVF cycles elsewhere, our center experience, likely, is predictive of where the practice of IVF is destined to go over the coming decades.

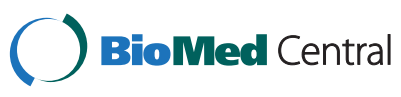

(c) 2014 Gleicher et al.; licensee BioMed Central Ltd. This is an Open Access article distributed under the terms of the Creative Commons Attribution License (http://creativecommons.org/licenses/by/4.0), which permits unrestricted use, distribution, and reproduction in any medium, provided the original work is properly credited. The Creative Commons Public Domain Dedication waiver (http://creativecommons.org/publicdomain/zero/1.0/) applies to the data made available in this article, unless otherwise stated. 
We, therefore, reviewed in addition to national U.S. trends, our center's 2010-2012 IVF outcome data, obtained in a uniquely adversely selected patient population, to assess outcome expectations, considering current practice patterns, for women above age 40 years. We, in addition, conducted a systemic search of the published literature on this subject.

This presentation, therefore, primarily is not meant as a presentation of original data but as a review of preliminary existing data, which may point towards where IVF practice, likely, is destined to go over the next two decades.

\section{Methods}

\section{IVF cycle outcomes}

Our center's IVF cycles, under a federally mandated law, are annually reported to the Centers for Disease Control (CDC) and voluntarily to the American Society for Reproductive Medicine (ASRM)/Society for Assisted Reproductive Technologies (SART).

In addition, every cycle is entered into the center's anonymized electronic research database, which served as one source for here reported center data for 2012 IVF cycles, together with the center's annual reports to CDC and ASRM/SART. 2013 outcome data were not yet complete by the time of this report.

\section{Our center's patient population}

Our center's IVF experience should be of special interest because of the patient population in which these outcomes were achieved. Based on review of 2010 and 2011 published CDC and ASRM/SART outcome reporting data, our center, proportionally, has been serving the largest percentage of women above age 42 years amongst all reporting ART centers in the U.S. Other adverse selection parameters for our center's patient population are, however, not public since they are not reported to either CDC and/or ASRM/ SART. Figures $1 \mathrm{~A}$ and B demonstrate that our center's patient population, indeed, does likely reflect the most adverse selection criteria of any reported IVF center in the U.S., if not worldwide.

Figure 1A demonstrated mean and median ages of our center's IVF patient population between 2006-2012. As the figure demonstrates, starting in 2010, our center experienced a significant increase in patient age, which even before already demonstrated a median population age around 38 years. Since 2010 the median age has, however, further increased to above age 40, with 2012 data suggesting that median age may soon reach age 41 .

The "graying" of the center's patient population is, however, not only demonstrated by increasing age. As Figure 1B demonstrates, concomitantly, the patients' anti-Müllerian hormone (AMH) levels at presentation significantly declined, indicating increasingly poor functional ovarian reserve (FOR) of treated patients. Before
2010, median AMH values hovered around $0.80 \mathrm{ng} / \mathrm{mL}$, already considered below favorable outcome levels for women with low FOR [4]; yet, starting in 2010, median AMH levels progressively decreased, reaching a nadir in 2012 below $0.40 \mathrm{ng} / \mathrm{mL}$, with preliminary 2013 data (not shown) suggesting further declines.

Concomitantly, in our center's 2012 annual CDC/SART submissions, $13.8 \%$ of all fresh IVF cycles occurred in women at ages $41-42$ years, $20.6 \%$ at ages $43-44$ years and $12.6 \%$ in women above age 46 years. This means that $47.0 \%$ of all fresh cycles involved women above age 41 and $33.2 \%$ of cycle women above age 43 years.

Considering these demographic data, it is not surprising that only $10.1 \%$ of fresh cycles were followed up by a frozen-thawed cycle during 2012 since women of advanced age and with low FOR rarely produce enough oocytes/ embryos for subsequent thaw cycles. Yet, despite performance of so many fresh IVF cycles in significantly aged women, still, in addition, $18.3 \%$ of all fresh cycles were donor egg cycles.

Further documentation of our center's adverse patient selection is the fact that between 2010-2012 in each year over $85 \%$ of newly presenting patients to our center had previously been in infertility treatments elsewhere and had failed at least one IVF cycle attempt. Most of these patients, indeed, had failed multiple IVF cycles, often at a number of different centers. In addition, the number of new long-distance patients, defined as patients from outside the larger New York City Tristate area, has been persistently increasing over the last five years, and in 2012 for the first time exceeded $60 \%$ of the centers total new patient population. Approximately two-third of longdistance patients come from the rest of the U.S. and Canada, and the rest from overseas.

Here presented data demonstrate that our center's current population during 2012 in more than half of all cases was of very advanced female age and/or suffered from very low FOR. While such extreme patient characteristics, currently, are not yet the norm at other IVF centers, trends in developed countries go into the same direction, as young and uncomplicated IVF patients quickly conceive, while older and more poor prognosis patients accumulate.

\section{Systematic literature review}

We searched PubMed, MEDLINE ${ }^{\ominus}$ and Google Scholar databases for multiple key words and phrases, referring to $<$ fertility $>$ and $<$ fertility treatments $>$ in $<$ older women $>$ or at $<$ advanced age $>$, including specific end points, like $<$ spontaneous pregnancies $>$, $<$ pregnancy rates $>$, $<$ in vitro fertilization (IVF) $>$, $<$ intrauterine insemination (IUI) $>$, $<$ miscarriages $>$, <pregnancy loss $>$, <aneuploidy $>$, $<$ medical complications of pregnancy $>$, <age related medical complications of pregnancy>, etc. 


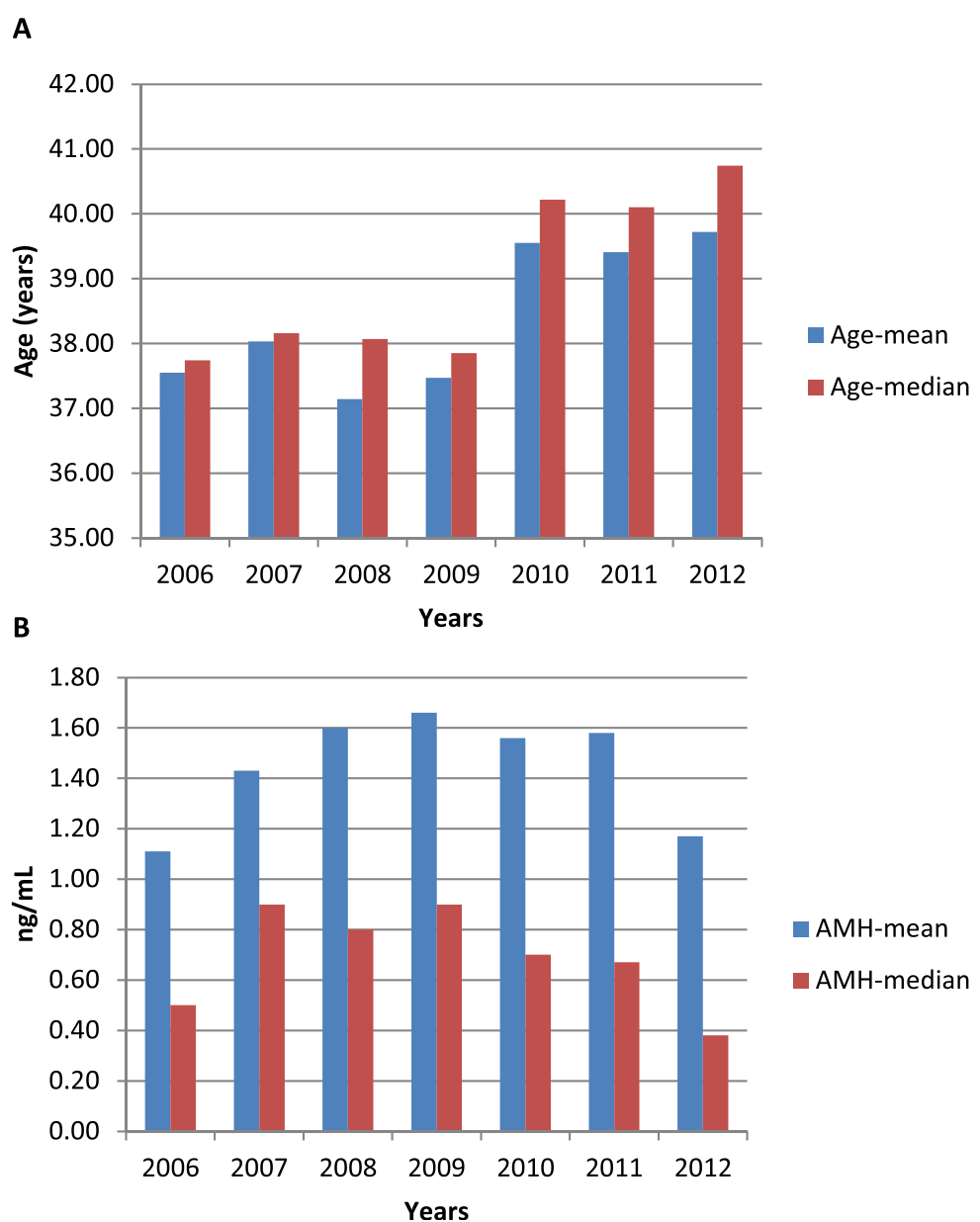

Figure 1 Our center's patient characteristics, years 2006-2012. A. Mean and median age of patients in years $2006-2012$ (in years). B. Mean and median $\mathrm{AMH}$ values $(\mathrm{ng} / \mathrm{mL})$ in years 2006-2012.

Data from the literature were initially extracted by one author (NG) and then reviewed by the three other authors (VAK, AW, DHB).

This search failed to reveal even a single clinical trial addressing fertility treatments in "older" women (>age 40 - 42 years), and also did not demonstrate even a single review on the subject. Whatever limited data are available, are here presented.

\section{Institutional Review Board (IRB)}

Our patients sign at initial consultation, as part of a universal HIPAA consent form, a statement that allows use of data from their medical records for reporting purposes to CDC, ASRM/SART and for research purposes, as long as their medical data remain confidential and their identity remains protected. Both conditions were met here. Since utilized data in here presented study only utilized anonymized statistical data sets, it did not require further IRB approval.

\section{Results}

Our center's 2010-2012 IVF outcome data

The center's annual 2010-2012 IVF outcome data are presented in Table 1. IVF outcomes are presented by "intent to treat", which means with reference point cycle start. Considering how adversely selected here reported patients are, this is important to note. Moreover, as noted under "Materials and Methods", a large majority of patients presenting to our center have failed prior IVF cycles elsewhere, often multiple cycles. Here reported 233 IVF cycles in most patients, therefore, followed prior failed IVF cycles elsewhere. In addition, a good number of here reported IVF cycles also represent repeat cycles at our center. IVF treatment outcomes, therefore, should at each age be significantly better than here reported if only first IVF cycles were to be considered. Such an analysis is, however, in here presented patient population not possible.

As Table 1 demonstrates, up to and inclusive of age 42 years, live birth rates are even in such an adversely 


\begin{tabular}{|c|c|c|}
\hline $\begin{array}{c}\text { Age } \\
\text { (years) }\end{array}$ & $\begin{array}{c}\text { Live birth } \\
\text { rate (\%) }\end{array}$ & $\begin{array}{l}\text { Clinical pregnancy } \\
\text { rate (\%) if different }\end{array}$ \\
\hline 40 & 15.4 & \\
\hline 41 & 42.9 & \\
\hline 42 & 6.3 & 18.8 \\
\hline 43 & 0.0 & 16.7 \\
\hline 44 & 1.4 & 5.4 \\
\hline 45 & 2.7 & 5.4 \\
\hline $46-53$ & 0.0 & \\
\hline
\end{tabular}

* "Intent to treat" reflects denominator of per cycle start for each age group. A total of 233 IVF cycles are reported. Because of an $\sim 20 \%$ cycle cancellation rate before embryo transfer, reports based on patients reaching embryo transfer of at least 1 embryo would demonstrate $\sim 20 \%$ higher clinical pregnancy and live birth rates.

**Miscarriages reflect only established clinical pregnancies, confirmed by ultrasound by presence of at least one intrauterine gestational sac. Chemical and ectopic pregnancies are not considered in here presented data.

selected patient population very respectable. Starting with age 43 years, there is a significant drop off in both clinical pregnancies and live births, as previously reported by our group for earlier years [5]. Above, and including age 46 years, pregnancy and delivery chances appear negligible, even though in 2013 our center established two, at this point ongoing clinical pregnancies, in women in their 46th year, which considering a small denominator, would reflect a respectable live birth rate if both pregnancies reach delivery (data not shown). Between 2010 - 2012 selected women up to age 53 were treated at our center, as Table 1 demonstrates.

It is also important to note that in women with still regular menses, at our center less than $20 \%$ fail to reach retrieval and/or transfer. This relative low cycle cancellation rate is based on our center's policy to go to retrieval even with single follicles, unless patients object or patients are not already on maximal ovarian stimulation.

Likely, because of dehydroepiandrosterone (DHEA) supplementation, which at our center is routine in women with low FOR, miscarriage rates in even very adversely selected patients have in the past been only $15.1 \%$ [6]. Since publication of this study, the degree of adverse selection of patients at the center has, however, further increased (Figures 1A\&B). During 2011-2012, miscarriage rates have, therefore, been in the $20.0-23.0 \%$ range. Table 1 demonstrates that miscarriages occurred primarily in the oldest patients. These data concur with our earlier report, which demonstrated that positive effects of DHEA on miscarriage rates progressively increase after age 35 but, of course, still increase with advancing female age [6].

Though overall modest, pregnancy rates obtained in a highly adversely selected patient population at our center, thus, clearly, at least up to and including age 42 but, likely, up to and including age 45 years, appear superior to the predominant opinions in the profession as to what is achievable in older women. Except for an outlier study by Ninimäki et al. [7], they also appear superior to studies we were able to discover in the literature on the subject (see below). They, of course, also exceed the definitions of the Ethics Committee of the ASRM for "futility" [8].

Our center's IVF outcomes before 2012 have been widely published [5,6,9-15]. We, therefore, conclude that, based on clinical as well as ethical consideration, currently available data under appropriate informed consents do support a more proactive treatment of older women than is currently the prevailing practice in the U.S. and Europe. This argument appears further supported by the previously noted observation that even better outcomes than reported here can be expected in less adversely selected patients at older ages. Finally, unless the profession initiates more active treatment of older women, it is unlikely that maximal possible progress will be made in treating such women. In medicine, only practice "makes perfect".

As important success of oocyte donation has become in offering maternity to older women, every egg donation, nevertheless, in at least some ways still represents treatment failures in a case of infertility. Rising numbers of oocyte donation cycles, as witnessed in many countries around the world, including the U.S., therefore, at least partially are a reflection of our profession's failure in helping many older women to conceive with use of autologous oocytes.

\section{What our center's IVF outcome data are based on}

Progress in treating older women is continuous. For example, it only recently became known that at ages low FOR is associated with low androgen levels [13-15], and that normal androgen levels (i.e., levels encountered in young women) are essential for early stages of follicle maturation $[16,17]$. We, therefore now pre-supplement older women with dehydroepiandrosterone (DHEA) in attempts to raise testosterone (T) levels [18]. Pregnancy chances in IVF depend on the degree of improvement in $\mathrm{T}$ levels after DHEA supplementation in such patients [13-15]. Indeed, we learned not to initiate IVF cycles in older women until $\mathrm{T}$ levels are in approximately the upper one-third of normal range or slightly above.

We also learned that so-called low-intensity cycles ("mini-IVF" or mild stimulation cycles) even in women with normal FOR produce inferior outcomes in comparison to standard IVF cycles $[19,20]$. Though a prospective clinical trial on this subject remains to be conducted, they, therefore, can be expected to produce even poorer outcomes in women with low FOR. In older women our center, therefore, practically universally only utilizes high dose gonadotropin stimulation in microdose-agonist cycles. 
Our evolving approach to "older" ovaries is best demonstrated in a recently published study of 128 consecutive infertile women with extremely low FOR, defined by AMH values below $0.4 \mathrm{ng} / \mathrm{m}$; many, indeed, had undetectable AMH levels. Their mean age was $40.8 \pm 4.1$ years, their mean baseline FSH was $15.7 \pm 11.1 \mathrm{mIU} / \mathrm{mL}$ and their mean $\mathrm{AMH}$ was a remarkable $0.2 \pm 0.1 \mathrm{ng} / \mathrm{mL}$. Even this extremely adversely selected patient population still recorded a 7.9 percent clinical pregnancy $(95 \% \mathrm{CI}$ : 4.9-11.9\%) per cycle, and a cumulative pregnancy rate of 15.6 percent ( $95 \%$ CI: $9.8-23.1 \%$ ) in up to three consecutive IVF cycles. As one would expect, age 42 years significantly differentiated between better and poorer pregnancy $(\mathrm{P}=0.013)$ and delivery chances $(\mathrm{P}=0.036)[5]$.

Combining these data, published in 2011 and reflecting preceding years, with here presented, more recent outcomes, some interesting additional conclusions relating to patient age and FOR, as represented by $\mathrm{AMH}$ values, become possible: Likely the most important one is the relative irrelevance of even extremely low FOR (low $\mathrm{AMH}$ levels) up to and including age 42. Both of these studies demonstrate very clearly that, even with extremely low AMH or even undetectable levels, younger women and older women up to and inclusive of age 42 years, still have surprisingly good clinical pregnancy and live birth chances with IVF treatments. With and above age 43 years, a remarkable further drop off can be observed but serial cycles, likely, still will allow for decent cumulative returns up to and inclusive of at least age 45 years [5] and Table 1.

It again is important to reemphasize that here reported outcomes, because of adverse patient selection, likely, represent worst case scenarios, and even better outcomes can be expected in less adversely selected patients of same ages.

Utilization of high dosage gonadotropin stimulation has remained controversial. In women pretreated with DHEA, such an approach, however, does appear effective as larger oocyte numbers lead to more available euploid embryos for transfer [21]. This is an important observation since colleagues who reported that aneuploidy increases with higher gonadotropin dosages are, likely, correct [22,23]. They, however, overlook that increases in aneuploidy percentages are more than compensated by increases in absolute embryo numbers with DHEA supplementation. Despite increases in percentage of aneuploid embryos with high gonadotropin stimulations, properly selected patients, therefore, nevertheless end up with a net benefit in number of transferrable embryos [21]. Other investigators concur with these conclusions [24,25].

In older women, we also fail to understand the widely utilized practice of culturing embryos to blastocyst stage (days-5/6) since embryos at advanced female ages in the laboratory only rarely survive to days $5 / 6$. Others share our opinion on this subject as well [26].
Since increasing numbers of IVF centers now, however, resort to routine blastocyst stage culture, including in women with low FOR and at advanced ages, we have had ample opportunities to treat women who failed multiple such attempts before presenting to our center. Though not a "controlled" study set up, we in a good number of such patients succeeded in establishing pregnancies (reaching normal delivery) who in repeated preceding cycles either failed to have embryos reach blastocyst stage and/or failed to reach embryo transfer for other reasons [27] and Gleicher N, unpublished data. This is also a reason why we oppose PGS in older women, when used to improve IVF outcomes [27]. PGS in older patients actually, for all of above noted reasons, appears to reduce pregnancy chances in association with IVF [28].

\section{Systematic literature review and discussion National U.S. aging trends}

Figure 2 summarizes national U.S. age distributions for IVF, reported to the CDC between 1997 and 2010 (Center for Disease Control and Prevention 2013). Till 2006 CDC published patient outcome data only up to age 42 years; since 2007 up to age 44 and, starting in 2010, also including women above age 44. In 1997 women under age 35 represented 44.7 percent of all fresh non-donor IVF cycles; by 2010, however, only 41.4 percent (Table 2 and Figure 2). Concomitantly, as further evidence for the "graying" of fertility care in the U.S., the number of donor egg cycles more than doubled between 1997 and 2010 (Table 2). Growth in donor egg cycles at our center also exceeded growth in fresh IVF cycles over the last five years (data not shown).

As women age, they require earlier utilization of IVF and higher medication dosages for ovarian stimulation. Increasing embryo aneuploidy with advancing maternal age [29], and increasing miscarriage risk [30], together with higher medication costs, lead to higher treatment costs per cycle, while efficacy of treatments declines in parallel [30]. Cost effectiveness of IVF, therefore, decreases with advancing female age (see also later).

Practically all infertility treatments convert natural, mono- follicular into poly-follicular cycles, increasing the risk of multiple births [31]. Older maternal age during 1980-2009 accounted for approximately one-third of the U.S. increase in twinning [32]. Bamberg et al. reported 34.4 percent of twin pregnancies to be due to infertility treatments, a 3.2-year increase in maternal mean age over their study period, more infertile women above age 35 than among spontaneously conceived twins (37.6\% vs. $22.9 \%$ ), and significantly higher mean ages (32.5 vs. 30.1 years) [33].

This development is at least partially driven by advancing female age and increasing length of infertility increasing the desire for multiple births [34]. The increasing complexities 


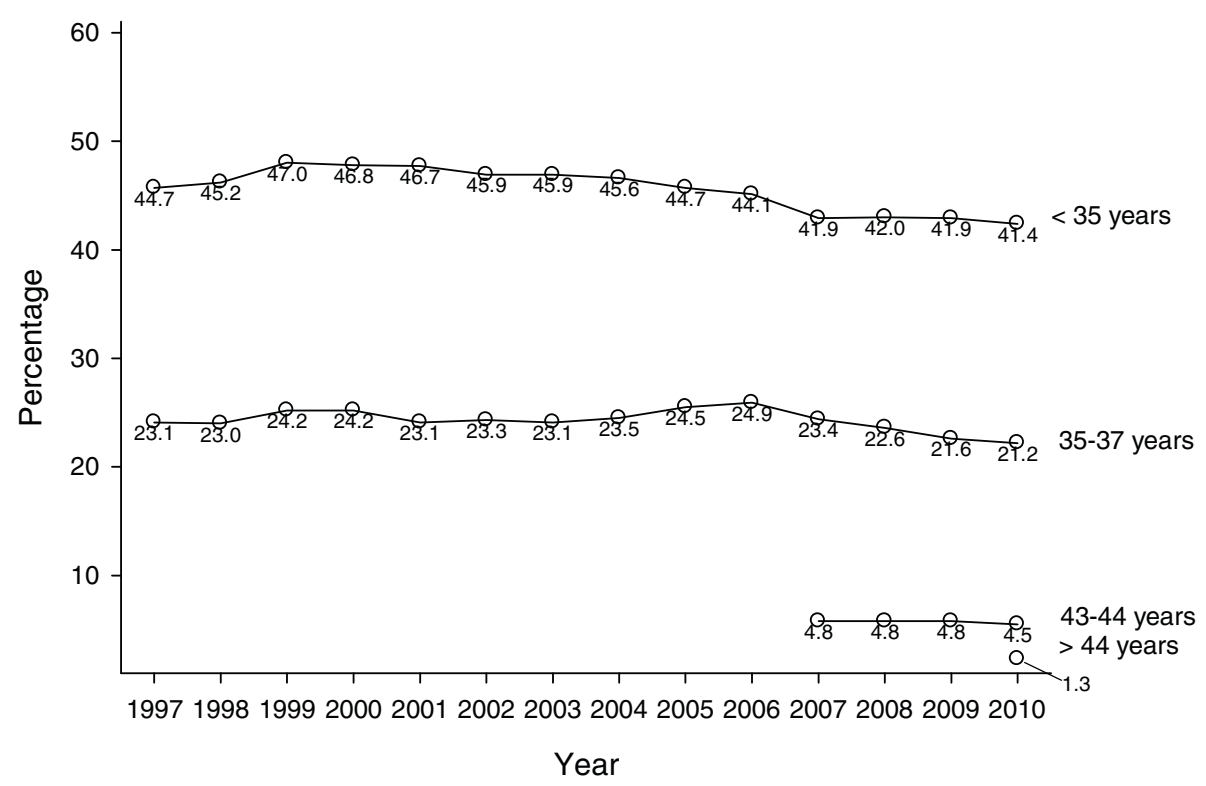

Figure 2 Percentage distribution of U.S. IVF cycles per age groups, years 1997-2010. The figure demonstrates in the young patient groups ( $<35$ years and 35-37 years) flat IVF cycle years for the period between 1997-2010, and even mild declines, starting in 2006/2006. In contrast, the oldest patient groups, before 2007 not even registered in national outcome reporting in the U.S., gathered steam. Starting in 2010, national outcome reporting for the first time, indeed, included women above age 44 years. All of these development also correlate well to reported U.S. data, suggesting that women above age 40 now represent the, proportionally, most rapidly age group of women having children $[1,2]$.

encountered by older women pursuing pregnancies and entering fertility care, therefore, are multifactorial (see also later).

\section{Limited access to care}

The increase in older women pursuing pregnancy is taking place against a background of considerable skepticism and even resistance from the U.S. government, the insurance industry and many colleagues in the medical community $[30,35,36]$.

In many European countries advanced age is often considered a categorical barrier to treatment. For example, in the UK coverage is limited to ages 23-39 years [37], though an expansion to age 42 has recently been proposed [38]. Sweden restricts access to fertility treatment after age 40-42 years [39], and Finland after age 40 years [40].

Table 2 Age distribution of U.S. IVF cycles 1997-2010

\begin{tabular}{|c|c|c|c|c|c|c|c|c|}
\hline & Total & $<35$ & $35-37$ & $38-40$ & $41-42$ & $43-44$ & $>44$ & $\overline{\text { Donor ETs }}$ \\
\hline 1997 & 55,042 & 24,581 (44.7\%) & $12,733(23.1 \%)$ & 10,997 (20.0\%) & 6,691 (12.2\%) & & & 4,498 \\
\hline 1998 & 61,650 & $27,858(45.2 \%)$ & $14,146(23.0 \%)$ & 12,037 (19.5\%) & 7,609 (12.3\%) & & & 5,308 \\
\hline 1999 & 63,123 & $29,682(47.0 \%)$ & $15,291(24.2 \%)$ & $12,848(20.4 \%)$ & $5,302(8.4 \%)$ & & & 5,844 \\
\hline 2000 & 71,556 & $33,453(46.8 \%)$ & $17,284(24.2 \%)$ & $14,701(20.6 \%)$ & $6,118(8.6 \%)$ & & & 6,731 \\
\hline 2001 & 77,102 & $35,984(46.7 \%)$ & $17,791(23.1 \%)$ & $16,283(21.1 \%)$ & $7,044(9.1 \%)$ & & & 7,722 \\
\hline 2002 & 81,888 & $37,591(45.9 \%)$ & $19,110(23.3 \%)$ & $17,454(21.3 \%)$ & $7,733(9.4 \%)$ & & & 8,394 \\
\hline 2003 & 86,753 & 39,852 (45.9\%) & $20,056(23.1 \%)$ & $18,660(21.5 \%)$ & 8,185 (9.4\%) & & & 8,970 \\
\hline 2004 & 89,535 & $40,853(45.6 \%)$ & $21,019(23.5 \%)$ & $19,174(21.4 \%)$ & $8,487(9.5 \%)$ & & & 9,283 \\
\hline 2005 & 92,405 & $41,302(44.7 \%)$ & $22,624(24.5 \%)$ & $19,482(21.1 \%)$ & 8,997 (9.7\%) & & & 9,649 \\
\hline 2006 & 93,866 & 41,369 (44.1\%) & $23,376(24.9 \%)$ & $19,775(21.1 \%)$ & 9,346 (10.0\%) & & & 10,049 \\
\hline 2007 & 100,592 & 42,127 (41.9\%) & $23,504(23.4 \%)$ & $20,612(20.5 \%)$ & $9,535(9.5 \%)$ & $4,814(4.8 \%)$ & & 10,321 \\
\hline 2008 & 103,104 & $43,296(42.0 \%)$ & $23,326(22.6 \%)$ & 21,793 (21.1\%) & $9,783(9.5 \%)$ & $4,907(4.8 \%)$ & & 10,718 \\
\hline 2009 & 101,090 & $42,384(41.9 \%)$ & $21,860(21.6 \%)$ & $22,144(21.9 \%)$ & $9,845(9.7 \%)$ & $4,857(4.8 \%)$ & & 10,151 \\
\hline 2010 & 100,824 & $41,744(41.4 \%)$ & $21,369(21.2 \%)$ & $21,741(21.6 \%)$ & $10,122(10.0 \%)$ & $4,501(4.5 \%)$ & 1,347 (1.3\%) & 9,866 \\
\hline
\end{tabular}


Cross-border medical tourism in search of fertility services has, therefore, greatly increased amongst older patients $[41,42]$. Our own center has witnessed a remarkable increased in older patients from Scandinavian countries over recent years, Particularly older Swedish patients in their country appear to face almost complete exclusion from access to fertility treatments, including from private centers. Prohibition of oocyte donation in many countries further exacerbates need for travel to receive fertility care [41].

In the U.S., restrictions are often more subtle. Medicaid and Medicare, the two federally funded government health care programs, do not offer coverage for IVF. The effects of the Affordable Care Act ("Obamacare") on IVF coverage are as of this point unpredictable, as is the future of the whole program, In the private insurance market age-linked restrictions greatly vary even within different insurance plans offered by the same insurance companies.

The medical profession, however, also contributes to some of the resistance in Europe and the U.S. Most fertility centers on both sides of the Atlantic maintain rigid age-cut offs and/or link denials of treatment to laboratory parameters, reflective of FOR. Indirectly, these laboratory parameters, of course, also reflect age [43], though patients may be unaware that, for all practical purposes, age-associated cut-offs are applied.

Our review of available data suggests that such ageassociated restrictions to treatment access lack basis in evidence since other factors than age also play major roles in determining pregnancy chances. Indeed what pregnancy chances are is often incorrectly assessed. For example, we find that patients frequently are advised that above age 40 years pregnancy chances from IVF and intrauterine inseminations (IUI) are similar. They, therefore, are refused IVF, and instead offered IUI cycles. Since 2001 the literature, however, suggests that IVF actually offers clearly superior pregnancy chances and time to conception at older ages in comparison to IUIs $[44,45]$.

Many colleagues also routinely advise patients that, above age 40 - 42 years, IVF live birth rates are in the 1-2\% range. As here presented data demonstrate, such a claim is, however, likely at least up to and inclusive of age 45 years unsupported, utilizing contemporary IVF standards of care, especially if patients are willing to consider consecutive cycles [5] and Table 1. Where this widely shared opinion originates is, therefore, unclear.

The most frequent reason for withholding infertility treatments amongst colleagues has been concern about cost-effectiveness of such treatments in older women $[43,46]$. Other motives, however, can also play a role: For example, since fertility centers often compete based on clinical pregnancy and delivery rates, lower pregnancy chances of older women can drag down a center's overall
IVF outcomes. In the U.S. such considerations are condemned by professional guidelines [8].

The obvious economic importance of pregnancy and delivery rates for IVF center was recently, however, again demonstrated when a small group of U.S. centers was reported to manipulate their contributions to the national outcome reporting system [47] by excluding unfavorable patients from reporting, either cancelling cycles before retrieval or avoiding reportable embryo transfers by cryopreserving all embryos without attempting a transfer [48].

Motivations for cycle cancellations can also contribute to outcome reporting biases: Some centers maintain unrealistic minimum follicle numbers for taking a patient to egg retrieval; others artificially increase cycle cancellations by routinely culturing embryos of older women's to day-5/6 blastocyst-stage instead of transferring on day- 3 [26]. A recently increasingly propagated protocol adds preimplantation genetic screening (PGS) after trophectoderm biopsy to routine IVF [49]. In older women only few embryos, however, usually survive to blastocyst stage, and even fewer will be euploid. So treated older women will, therefore, only infrequently reach embryo transfer and, therefore, escape reporting requirements [26,27,48]. Reported IVF pregnancy and delivery rates in such cases, therefore, are misleading since they are not calculated by "intent to treat" (i.e., cycle start) but use as reference point embryo transfer, which older women, of course, only rarely achieve.

\section{When should treatment be considered futile?}

For colleagues concerned about cost effectiveness of IVF at advanced patient ages, the central question becomes at what point treatments should be considered futile. The Ethics Committee of the ASRM defines "futility" as equal to or less than a one-percent chance of live birth. A "very poor" prognosis, in contrast, is defined by low but not nonexistent chances of live births ( $>1 \%$ to $\leq 5 \%$ per treatment cycle) [8].

Most colleagues providing fertility services on both sides of the Atlantic, currently, likely, consider almost all women above age 40-42 to fall into these two patient categories. Under guidelines from the Ethics Committee of the ASRM, physicians, therefore, may under such circumstances refuse treatment of patients. These guidelines, however, also recommend that, in case of treatment refusal, such patients be referred to providers who do offer treatment to older patients. This, however, rarely, if ever, happens because affected patients usually are advised that their only chance of pregnancy is with help of donor oocytes. As already noted before, the literature would suggest that this is incorrect advice [5] and Table 1, and many patients consider oocyte donation only a second-best choice. 


\section{Reported clinical outcome data in older women}

Our search failed to locate convincing evidence for reliable age-specific IVF outcome reports above age 40-42. Table 3 summarizes limited published data on the subject: Spandorfer et al. reported on 288 women above age 44 years (mean $45.4 \pm 0.73$ ). Only 161 among them reached retrieval (clinical pregnancy rate $21.2 \%$, miscarriage rate $85.3 \%$ ), resulting in a disappointing live birth rate of only 3.1\% [50].

Tsafrir et al. reported pregnancy and delivery rates of $13.9 \%$ and $9.1 \%$ at age 40 , and $2.8 \%$ and $0.7 \%$ by age 45 years [45], Italian investigators reported a clinical pregnancy rate of $5.8 \%$ in women 40 or older per cycle start, and $10.5 \%$ per transfer [51]. Hourvitz et al. reported a clinical pregnancy rates per cycle start of $7.7 \%$ at age $42,5.4 \%$ at age 43 , and $1.9 \%$ at age 44 , concluding that IVF should be restricted to under age 43 years [35]. As noted before, reviewing the literature Tsafrir et al. concluded that IVF, despite low pregnancy rates $(<5 \%)$, was preferable to IUI in women above age 40-41 [45].

In 2011 professional societies in Canada published a whitepaper, which, without quoting pregnancy expectations, noted that above age 40 IVF should be considered after only one or two failed cycles of controlled ovarian stimulation [52].

Table 3 Reported pregnancy rates in infertile women above age 40

\begin{tabular}{|c|c|c|c|c|}
\hline Author & IUI/IVF & $\%$ pregnancies & $\begin{array}{l}\% \text { live } \\
\text { births }\end{array}$ & $\begin{array}{c}\text { Year of } \\
\text { reference }\end{array}$ \\
\hline Spandorfer et al. ${ }^{1}$ [50] & IVF & 21.2 & 3.1 & 2007 \\
\hline Tsafrir et al. [45] & IUI/IVF & & & 2009 \\
\hline Age 40 & & 13.9 & 9.1 & \\
\hline Age 45 & & 2.8 & 0.7 & \\
\hline Schimberni et al. [51] & IVF & & & 2009 \\
\hline Per cycle & & 5.8 & & \\
\hline Per transfer & & 10.5 & & \\
\hline Hourvitz et al. [35] & IVF & & & 2009 \\
\hline Age 42 & & 7.7 & & \\
\hline Age 43 & & 5.4 & & \\
\hline Age 44 & & 1.9 & & \\
\hline $\begin{array}{l}\text { Marinakis and } \\
\text { Nikolaou [36] }\end{array}$ & IVF & & & 2011 \\
\hline Age $40-42$ & & & 11.0 & \\
\hline Age 43-44 & & & 4.6 & \\
\hline Age $>44$ & & & $<4.0$ & \\
\hline Ninimäki et al. ${ }^{2}$ [7] & IVF & & & 2012 \\
\hline 1 embryo ET & & 19.5 & 11.0 & \\
\hline 2 embryo ET & & 23.5 & 13.6 & \\
\hline
\end{tabular}

${ }^{1}$ After reviewing the literature, concluded that after age 40-41 IVF was preferable to IUI;

${ }^{2}$ Reflects patients between ages $40-44$ years;

$\mathrm{ET}$, embryo transfer.
Marinakis and Nikolaou reported live births rates in the United Kingdom (UK) of $11.0 \%$ at ages $40-42$, $4.6 \%$ at ages $43-44$ and less than $4.0 \%$ above age 44 [36]. Soullier et al. reported delivery rates of 4.0 percent for women above age 40 [53]. Analyzing 124,148 IVF cycles (33,514 live births) in the U.K., Lawlor and Nelson reported that two embryos transfers increased odds of live births at ages 40 or older more than in younger women, demonstrating that outcomes in older women can be improved by increasing embryo numbers transferred [54]. Ninimäki et al. were outliers in their outcomes, reporting with transfer of two and one embryo, respectively, pregnancy rates of 23.5 and 19.5 percent and live birth rates of 13,6 and 11.0 percent between ages 40-44 [7].

Skepticism towards treatment of older women is understandable, considering such limited and generally low reported outcome data. Lack of evidence in favor of treatment should, however, not be misconstrued as evidence in favor of no treatment.

Available data, therefore, have to be analyzed with caution. They suggest that: (i) only few centers worldwide routinely treat older women to IVF cycle completion; (ii) older patients, therefore, frequently are not given the opportunity to benefit from current state-of-the-art IVF treatments; Consequently, (iii) available outcome data are insufficient. Maybe most importantly, however, (iv) absence of controlled treatment attempts of older women with use of their own oocytes prevents improvements in treatment outcomes of such patients, creating a vicious circle to the detriment of older women,

\section{Patient autonomy}

Agreeing with a recently voiced ethical opinion by French colleagues in association with IVF [55], our center advocates patient autonomy in all decision-making processes in association with IVF. We fully support the deliberative, case-by-case approach, advocated by these authors in allowing patients to reach informed decisions. As part of this process we see it as our responsibility as physicians, at all stages, to (i) inform patients in unbiased form about their options, and (ii) advise patients, based on our own center's outcome data, what their chances of treatment success/failure are with each treatment option. We then defer to the patients' decisions, as long as they do not unreasonably endanger their own wellbeing or that of their potential offspring(s). Above age 45 years, the process, therefore, involves extensive medical as well as psychosocial evaluations of patients.

This approach makes infertility treatments at our center, in principle, available to almost all patients who are not in menopause $(\mathrm{FSH} \geq 40.0 \mathrm{mIU})$, and explains the extreme adverse selection of our center's patient population, described earlier. 
Patient autonomy also deserves consideration wen women are emotionally not ready to proceed into oocyte donation. Often they, first, have to convince themselves that they have exerted maximal efforts with use of their own eggs. Advising such women that oocyte donation represents their only reasonable chance of pregnancy is, therefore, often not enough. They frequently require additional cycle attempts with their own ovaries before reaching a point of conviction that allows them to proceed with donor eggs.

We consider it appropriate to offer these opportunities, since women who are prematurely "forced" into egg donation for the rest of their lives may second-guess their decision, even if they successfully conceived and delivered. Indeed, the newborn child may become the source of this second-guessing, which in rare instances can lead to significant psychological complications in the mother/child relationship, even rejection of the child by the mother (Gleicher N, unpublished data).

\section{Cost-effectiveness}

As noted earlier, cost-effectiveness is often the principal argument against treating older patients [30]. Paradoxically, this is an argument most prevalent in countries perceived as "social" in political outlook, like, for example, in the Scandinavian countries, These countries often do not consider expenditures on fertility treatments in older women to meet minimum thresholds of cost effectiveness [40]. Insurance companies in the United States (U.S.) have in some states voiced similar arguments in support of age restrictions in coverage of fertility services or in opposition to mandated insurance coverage for fertility services [56,57].

Age-dependent rationing of medical care is a widely accepted concept in many European countries [40], while fear of such rationing in the U.S. has been a major reason for opposition to the recently passed Affordable Care Act ("Obamacare") [58]. Defining cost-effectiveness of infertility care is, therefore, as much an economic as a political issue, often as much affected by geopolitical considerations as by pure cost considerations.

The state of Israel is a good example: With the highest utilization of IVF in the world (1657 IVF cycles/million citizens/year), this small country performs almost twice the number of IVF cycles of Iceland, the second highest utilizing nation [59]. The reason is that the Israeli government considers any subsidy of IVF, at almost all ages, "costeffective" because population growth is considered essential to its economic development and national security [60].

This can be contrasted with the Canadian province of Québec, where the state government only agreed to assume costs for IVF coverage in return for a commitment by the local provider community to reduce twin pregnancies by accepting a single embryo transfer (e-SET) mandate
[61]. Québec and Israel's governments, thus, very obviously, reached very different "cost-effectiveness" conclusions. Aside from remaining questions whether twin pregnancies really increase health care costs, considering the loss of life-long economic benefits from "lost" births in Québec, one has to wonder whether the province's decision, indeed, can be considered "cost-effective" [62].

Objective assessments of cost-effectiveness are further complicated by the greatly varying methods in how costeffectiveness is assessed in different countries. In The Netherlands, Evers, for example, calculated the lifelong contribution of every newborn to the growth national product (GNP) at $€ 1,848,320$, while societal costs, including childcare, education social welfare and health care costs add up to only $€ 1,610,000$. He concluded that every birth leaves Dutch society with a net-gain of approximately $€ 238,320$ (US\$ ca. 303,000), in his opinion rendering the funding of IVF up to age 44 years cost effective [63]. We are unaware of similar studies in other countries, and Evers' calculations for The Netherlands are, of course, not universally applicable.

\section{Further legal and ethical considerations}

Whether older women should be afforded a chance of conceiving is also a question with significant legal and ethical dimensions. Achieving motherhood represents fulfillment of a most basic human need (Perla L [64]; Smajdor A, [65]). Not to consider this fact, even in associations with costeffectiveness considerations, therefore, appears inhumane.

The concept of universal reproductive rights is based on the recognition that individuals have the absolute right to decide freely and responsibly about number, spacing and timing of their children, free of discrimination (which includes age-discrimination), coercion and violence (Gender and reproductive rights home page, 2013).

Like other patients, older women are entitled to ethical treatment, including autonomy (of decision making), beneficence, non-maleficence and justice. A number of ethicists have addressed the desire of older women to conceive: Perla, emphasizes respect for personal patient autonomy and staff empathy [64]. Smajdor notes that, with IVF representing medical treatment, it would be unethical to use it as a means of social control, providing or withholding it on basis of moral judgments about a patient's values or her lifestyle [65].

Delaying childbearing cannot simply be explained by the public's ignorance of appreciating the biological relationship between female aging and female ability to conceive [66]. Society, therefore, has to accept that the increase in the number of older women having children to a significant degree is caused by objective societal developments, and not the personal fancy of only a few outliers. 


\section{Effects on pregnancy management}

With advancing age women develop increasing numbers of medical disorders [67]. At least some of these conditions, for example autoimmune diseases, can affect fertility potential $[68,69]$ and/or raise outcome risks for mothers and offspring [69-73]. Prospective risk management, therefore, becomes essential in older women to avoid preventable pregnancy losses and other complications at varying gestational stages.

In older women fertility treatments, therefore, require increased attention to confounding medical problems, not always easily apparent in routine pre-IVF evaluations. Testing requirements, therefore, increase, as do consultations from other medical specialties. Not to be forgotten are socio-economical evaluations since any desire for motherhood at advanced age needs to be matched by social and economic abilities to parent a child, and to care for the child's upbringing.

As medical complications are more commonplace in older women, medical providers, including obstetricians, perinatologists, neonatologists and consultants from other medical specialties, have to be ready for an increasing volume of more complicated pregnancies, $[70=73]$. Increasing adverse maternal and neonatal outcomes have to be expected as a consequence.

These evolving changes have not been appreciated in full. For example, our medical specialty has largely failed to recognize the contribution of older women to the increased numbers of multiple births, mostly twins [31-33], while concentrating on IVF in criticism [74,75]. Only a very recently published study for the first time acknowledged the contribution of an aging infertility population to the multiple pregnancy issue, following fertility treatments [76].

Putting aside whether twins really represent adverse outcomes of infertility treatments [77], older women face different risk/benefit consideration than younger patients. Almost two decades ago, we for the first time reported on the strong desire of infertility patients to conceive twins, which increases with length of infertility and advancing patient age [34]. Those sentiments should not surprise, as older women have lower chances and less time to complete their families. Scotland et al. more recently in a European patient population noted that patients, therefore, are willing to take carefully considered, and educated risks to compensate for their lower pregnancy chances [78]. Can older women, therefore, really be blamed for, at times, making different risk/benefit choices than younger women?

\section{A brief discussion of our center's data}

We previously noted under materials and methods that our here presented outcome data in older women have to be viewed with caution because they were achieved in a highly adversely selected patient population who, almost uniformly, were on supplementation with DHEA. Such supplementation has still remained somewhat controversial in its efficacy. While it would exceed the framework of this manuscript to document the rational of this treatment approach in older women, suffice to say that our analysis of published data, relying on animal as well as human data, strongly supports supplementation of older women with androgens due to a relative hypoandrogenemia in such patients in comparison to younger ages $[14,15]$. A relative recent review of the subject was published, to which interested readers are referred $[17,18]$.

\section{Conclusions}

Reproductive medicine is inching ever closer towards technical abilities, which will allow for successful reproduction, almost independent of female age. Recent evidence that sperm and oocytes can be derived from testicular [79] and ovarian stem cells [80], and that even pluripotent adult stem cells can be used to produce gametes $[81,82]$, will, likely, make age-independent human reproduction a clinical reality within the foreseeable future. If progress in infertility treatments over the last 10-20 years has generated a pregnancy boom for women in their 40s, independence from ovarian and testicular senescence will expand this boom into the females' 50s and, maybe, even $60 \mathrm{~s}$.

Societal consequences will be highly significant: With women's lifespans in many industrialized countries now exceeding 80 years, even 50 -year old mothers now will have postmenopausal life expectancies exceeding postmenarcheal life expectancies of much younger mothers at the beginning of the $20^{\text {th }}$ Century. Women, therefore, will increasingly give birth to children at what, just one to two generations ago, used to be grandparental ages. Consequences will not only be medical in nature but will permeate all aspects of modern society. Against a backdrop of already budget-bursting health care costs, medical practice and society better get ready for this revolution!

\section{Abbreviations}

AMH: Anti-Müllerian hormone; CDC: Centers for Disease Control and Prevention; DHEA: Dehydroepiandrosterone; DOR: Diminished ovarian reserve; EC-ASRM: eSET, Elective single embryo transfer; FOR: Functional ovarian reserve; FSH: Follicle stimulating hormone; HEFA: Human Fertilisation and Embryology Authority; hMG: Human menopausal gonadotropin; IUI: Intrauterine insemination; IVF: In vitro fertilization; PGS: Preimplantation genetic screening; POA: Premature ovarian aging; OPOI: Occult primary ovarian insufficiency; OR: Ovarian reserve; T: Testosterone; U.K: United Kingdom; U.S: United States.

\section{Competing interests}

All four authors received grant support, travel funds and speaker honoraria from pharmaceutical and medical device companies, none, however, related to this manuscript. N.G. and D.H.B. are co-inventors of already awarded and still pending patents, relating to (i) supplementation of women with dehydroepiandrosterone (DHEA) and other androgens to improve conception and delivery chances, and (ii) use of FMR1 gene mutations to assess risk towards premature ovarian aging and potential cancer-causing effects in association with BRCA mutations. N.G. is owner of CHR-NY, and owns shares in fertility Nutraceuticals, LLC. N.G. and D.H.B 
receive patent royalties from this company. N.G. and D.H.B, own shares in LifeCycle Laboratories LLC and have licensed FMR1 patents to this company. V.A.K. serves as a consultant to the Centers for Disease Control (CDC) in regards to national ART outcome reporting. A.W. has no potential conflicts to report.

\section{Authors' contributions}

Study concept and design: NG Acquisition of data: NG, VAK, DHB Analysis and interpretation of data: NG, VAK, DHB. Drafting of the manuscripts: NG Critical revision of the manuscript: NG, VK, AW, DHB. All authors read and approved the final manuscript.

\section{Acknowledgements}

Funded by salary support from The Center for Human Reproduction - New York.

\section{Author details}

${ }^{1}$ Center for Human Reproduction, New York, NY 10021, USA. ${ }^{2}$ Foundation for Reproductive Medicine, New York, NY 10021, USA. ${ }^{3}$ Department of Gynecologic Endocrinology and Reproductive Medicine, Medical University Vienna, Vienna 1090, Austria.

Received: 17 April 2014 Accepted: 6 July 2014

Published: 9 July 2014

\section{References}

1. Hamilton BE, Martin JA, Sutton PD: Births: preliminary data for 2002. Natl Vital Stat Rep 2003, 51:1-20.

2. Hamilton BE, Martin JA, Sutton PD: Births: preliminary data for 2003. Natl Vital Stat Rep 2004, 53:1-17.

3. Bhattacharya S, Maheshwani A, Mollison J: Factors associated with failed treatment: an analysis of 121,744 women embarking on their first IVF cycles. PLoS One 2013, 8(12):e82249.

4. Gleicher N, Weghofer A, Barad DH: Anti-Mūllerian hormone (AMH) defines, independent of age, low versus good-live-birth chances in women with severely diminished ovarian reserve. Fertil Steril 2010, 94:2824-2827.

5. Weghofer A, Dietrich W, Barad DH, Gleicher N: Live birth chances in women with extremely low-serum anti-Mullerian hormone levels. Hum Reprod 2011, 26:1905-1909.

6. Gleicher N, Ryan E, Weghofer A, Blanco-Meija S, Barad DH: Miscarriage rates after dehydroepiandrosterone (DHEA) supplementation in women with diminished ovarian reserve: a case control study. Reprod Biol Endocrinol 2009, 7:108.

7. Niinimäki M, Suikkari AM, Mäkinen S, Söderström-Anttila V, Martikainen $\mathrm{H}$ : Elective single-embryo transfer in women aged $40-44$ years. Hum Reprod 2013, 28:331-335.

8. Ethics Committee of the American Society for Reproductive Medicine 2012: Fertility treatment when the prognosis is very poor or futile: a committee opinion. Fertil Steril 2012, 98:e6-e9.

9. Barad D, Brill H, Gleicher N: Update on the use of dehydroepiandrosterone supplementation among women with diminished ovarian function. J Assist Reprod Genet 2007, 24:629-634.

10. Gleicher N, Weghofer A, Barad DH: Improvement in diminished ovarian reserve after dehydroepiandrosterone supplementation. Reprod Biomed Online 2010, 21:360-365.

11. Gleicher N, Weghofer A, Barad DH: Dehydroepiandrosterone (DHEA) reduces embryo aneuploidy: direct evidence from preimplantation genetic screening (PGS). Reprod Biol Endocrinol 2010, 8:140.

12. Barad DH, Weghofer A, Gleicher N: Utility of age-specific serum antiMüllerian hormone concentrations. Reprod Biomed Online 2011, 22:284-291.

13. Weghofer A, Kim A, Barad DH, Gleicher N: The impact of androgen metabolism and FMR1 genotypes on pregnancy potential in women with dehydroepiandrosterone (DHEA) supplementation. Hum Reprod 2012, 27:3287-3293.

14. Gleicher N, Kim A, Weghofer A, Shohat-Tal A, Lazzaroni E, Lee HJ, Barad DH: Starting and resulting testosterone levels after androgen supplementation determine at all ages in vitro fertilization (IVF) pregnancy rates in women with diminished ovarian reserve (DOR). J Assist Reprod Genet 2013, 30:49-62.

15. Gleicher N, Kim A, Weghofer A, Kushmir VA, Shohat-Tal A, Lazzaroni E, Lee H-J, Barad DH: Hypoandrogenism in association with diminished functional ovarian reserve. Hum Reprod 2013, 28:1084-1091.
16. Sen A, Hammes SR: Granulosa-cell specific androgen receptors are critical regulators of ovarian development and function. Mol Endocrinol 2010, 24:1393-1403.

17. Gleicher N, Weghofer A, Barad DH: The role of androgens in follicle maturation and ovulation: friend or foe of infertility treatment? Reprod Biol Endocrinol 2011, 9:116.

18. Gleicher N, Barad DH: Dehydroepiandrosterone (DHEA) supplementation in diminished ovarian reserve (DOR). Reprod Biol Endocrinol 2011, 9:67.

19. Gleicher N, Weghofer A, Barad DH: Low-intensity IVF: real progress? Reprod Biomed Online 2011, 23:274-278.

20. Gleicher N, Weghofer A, Barad DH: A case-control pilot study of low-intensity IVF in good- prognosis patients. Reprod Biomed Online 2012, 24:396-402.

21. Gleicher N, Kim A, Weghofer A, Barad DH: Lessons from elective in vitro fertilization (IVF) in, principally, non-infertile women. Reprod Biol Endocrinol 2012, 10:48.

22. Fauser BCJM, Nargund G, Nyboe Andersen A, Norman R, Tarlatzis B, Bolvin J, Ledger W: Mild ovarian stimulation for IVF: 10 years later. Hum Reprod 2010, 25:2678-2684.

23. Zarek SM, Muasher SJ: Mild minimal stimulation for in vitro fertilization: an old idea that needs to be revisited. Fertil Steril 2011, 95:2449-2455.

24. Revelli A, Casano S, Salvagno F, Delle Piane L: Milder is better? Advantages and disadvantages of "mild" ovarian stimulation for human in vitro fertilization. Reprod Biol Endocrinol 2011, 9:25.

25. Siristatidis C, Trivella M, Chrelias C, Sioulas VD, Vrachnis N, Kassanos D: A short narrative review of the feasibility of adopting mild ovarian stimulation for IVF as the current standard of care. Arch Gynecol Obstet 2012, 286:505-510.

26. Cedars Ml: National reporting of in vitro fertilization success rates: how do we get patients useful information? Fertil Steril 2013, 100:1210-1211.

27. Gleicher N, Barad DH: A review of and commentary on the ongoing second clinical introduction of preimplantation genetic screening (PGS) to routine IVF practice. J Assist Reprod Genet 2012, 29:1159-1166.

28. Mastenbroeks S, Twisk M, van der Veen F, Repping S: Preimplantation genetic screening: a systematic review and meta-analysis of RCTs. Hum Reprod Update 2011, 17:454-466

29. Pal L, Santoro N: Age-related decline in fertility. Endocrinol Metab Clin North Am 2003, 32:669-688.

30. Maheshwari A, Scotland G, Bell J, McTavish A, Hamilton M, Bhattacharya S: Direct health service costs of providing assisted reproduction services in older women. Fertil Steril 2010, 93:527-536.

31. Practice Committee of the American Society for Reproductive Medicine: Multiple gestation associated with infertility therapy: an American Society for Reproductive Medicine Practice Committee opinion. Fertil Steril 2012, 97:825-834.

32. Martin JA, Hamilton BE, Osterman MJ: Three decades of twin births in the United States, 1980-2009. NCHS Data Brief 2012, 80:1-8

33. Bamberg C, Fotopoulou C, Neissner P, Slowinski T, Dudenhausen JW, Proquitte $\mathrm{H}$, Bührer $\mathrm{C}$, Henrich W: Maternal characteristics and twin gestation outcomes over 10 years: impact of conception methods. Fertil Steril 2012, 98:95-101.

34. Gleicher N, Campbell DP, Chan CL, Karande V, Rao R, Balin M, Pratt D: The desire for multiple births in couples with infertility problems contradicts present practice patterns. Hum Reprod 1995, 10:1079-1084.

35. Hourvitz A, Machtinger R, Maman E, Baum M, Dor J, Levron J: Assisted reproduction in women over 40 years of age: how old is too old? Reprod Biomed Online 2009, 19:599-603.

36. Marinakis G, Nikolaou D: What is the role of assisted reproductive technology in the management of age-related infertility? Hum Fertil (Camb) 2011, 14:8-15.

37. Human Fertilisation \& Embryology Authority. http://www.hfea.gov.uk/ fertility-treatment-cost-nhs.html.

38. Campbell D: IVF treatments extended to women up to age 42 on NHS. Guardian 2012, [http://www.theguardian.com/society/2012/may/22/ivf-nhsage-42-fertility] Accessed July 7, 2014

39. Zeger-Hochschild F, Nygren KG, Ishihara O: The impact of legislation and socioeconomic factors in the access to and global practice of assisted reproductive technology (ART). http://www.eticayreproduccionhumana. udp.cl/pubicaciones/lecturas/impact_legislation.pdf].

40. Klemetti R, Gissler M, Sevón T, Hemminki E: Resource allocation of in vitro fertilization: a nationwide register-based cohort study. BMC Health Service Res 2007, 7:210. 
41. Zanini G: Abandoned by the State, betrayed by the Church: Italian experiences of cross-border reproductive care. Reprod Biomed Online 2011, 23:565-572.

42. Inhorn MC, Patrizio P: The global landscape of cross-border reproductive care: twenty key findings for the new millennium. Curr Opin Obstet Gynecol 2012, 24:158-163.

43. Nelson SM, Telfer EE, Anderson RA: The ageing ovary and uterus: new biological insights. Hum Reprod Update 2013, 19:67-83.

44. Auyeung A, Klein ME, Ratts VS, Odem RR, Williams DB: Fertility treatment in the forty and older women. J Assist Reprod Genet 2001, 18:638-643.

45. Tsafrir A, Simon A, Margalioth EJ, Laufer N: What should be the first-line treatment for unexplained infertility in women over 40 years of age-ovulation induction and IUI, or IVF? Reprod Biomed Online 2009, 19(Suppl 4):4334.

46. Connoly MP, Hoorens S, Chambers GM, on behalf of the ESHRE Reproduction and Society Task Force: The costs and consequences of assisted reproductive technology on economic perspectives. Hum Reprod Update 2010, 16:603-613.

47. Fertility Clinic Success Rate and Certification Act of 1992. In HR 4773ENR, 102 Cong (1991-1992). Pub L No. 102-493.

48. Kushnir VA, Vidali A, Barad DH, Gleicher N: The status of public reporting of clinical outcomes in assisted reproductive technology (ART). Fertil Steril 2013, 100:736-741.

49. Scott RT Jr, Upham KM, Forman EJ, Hong KH, Scott KL, Taylor D, Tao X Treff NR: Blastocyst biopsy with comprehensive chromosomal screening and fresh embryo transfer significantly increasing in vitro fertilization implantation and delivery rates: a randomized controlled trial. Fertil Steril 2013, 100:697-703.

50. Spandorfer SD, Bendikson K, Dragisic K, Schattman G, Davis OK, Rosenwaks $Z$ : Outcome of in vitro fertilization in women 45 years and older who use autologous oocytes. Fertil Steril 2007, 87:74-76.

51. Schimberni M, Morgia F, Colabianchi J, Giallonardo A, Piscitelli C, Giannini P, Montigianini M, Sbracia M: Natural-cycle in vitro fertilization in poOr responder patients: a survey of 400 consecutive cycles. Fertil Steril 2009, 92:1297-1301.

52. Reproductive Endocrinology and Infertility Committee; Family Physician Advisory Committee; Maternal-Fetal Medicine Committee; Executive and Council of the Society of Obstetricians, Liu K: Case A. Advanced reproductive age and infertility. J Obstet Gynecol Can 2011, 33:1165-1175.

53. Soullier N, Bouyer J, Pouly JL, Guibert J, de La Rochebrochard E: Effect of the woman's age on discontinuation of IVF treatment. Reprod Biomed Online.

54. Lawlor DA, Nelson SM: Effect of age on decisions about the number of embryos to transfer in assisted conception: a prospective study. Lancet 2012, 379:521-527. Erratum Lancet 2012, 379:894.

55. Jean M, Tessier P, Bonnaud-Antignac A, Freour T, Barriere P, Dabouis G: Is the debate about single or double embryo transfer following in vitro fertilization really an ethical dilemma? Clin Ethics 2013, 8:61-69.

56. Gleicher N: Strategies to improve insurance coverage for infertility services. Fertil Steril 1998, 70:1006-1008

57. Gleicher N, Weghofer A, Barad D: Too old for IVF: are we discriminating against older women? J Assist Reprod Genet 2007, 24:639-644.

58. Hsieh P: Get ready for Obamacare's medical rationing. Forbes 2012, [http://www.forbes.com/sites/paulhsieh/2012/10/03/get-ready-forobamacares-medical-rationing/] Accessed July 7, 2014.

59. Collins JA: An international survey of the health economics of IVF and ICSI. Hum Reprod Update 2002, 8:265-277.

60. Kraft D: Where families are priced, help is free. In The New York Times. 2012.

61. Bissonnette F, Phillips SJ, Gunby J, Holzer H, Mahutte N, St-Michel P, Kadoch IJ: Working to eliminate multiple pregnancies: a success story in Québec. Reprod Biomed Online 2011, 23:500-504.

62. Gleicher N: Eliminating multiple pregnancies: an appropriate target for government intervention? Reprod Biomed Online 2011, 23:401-406.

63. International Federation of Infertility Societies: IVF is cost-effective, and should not be limited by age. http://www.iffs-reprodution.org/documents/ Evers_Final.pdf.

64. Perla L: Is in-vitro fertilization for older women ethical? Personal Perspective Nurs Ethics 2001, 8:152-158.

65. Smajdor A: The ethics of IVF over 40. Maturitas 2011, 69:37-40.

66. Mac Dougal K, Beyene Y, Nachtigall RD: Age shock: misperceptions of the impact of age on fertility before and after IVF in women who conceive after age 40. Hum Reprod 2013, 28:350-356.
67. O'Reilly-Green C, Cohen WR: Pregnancy in women aged 40 and older. Obstet Gynecol Clin North Am 1993, 20:313-331.

68. Gleicher N, Vidali A, Karande V: The immunological "Wars of the Roses": disagreements amongst reproductive immunologists. Hum Reprod 2002, 17:539-542

69. Sen A, Kushnir VA, Barad DH, Gleicher N: Endocrine autoimmune diseases and female infertility. Nat Rev Endocrinol 2014, 10:37-50.

70. Leary PJ, Leary SES, Stout KK, Schwartz SM, Easterling TR: Maternal, perinatal and postneonatal outcomes in women with chronic heart disease in Washington State. Obstet Gynecol 2012, 120:1283-1290.

71. Lamminpää R, Vehviläinen-Julkunen K, Gissler M, Heinonen S: Preeclampsia complicated by advanced maternal age:a registry-based study on primiparous women in Finland 1997-2008. BMC Pregnancy Childbirth 2012, $12: 47$

72. Kort DH, Gosselin J, Choi JM, Thornton MH, Cleary-Goldman J, Suaer MV: Pregnancy after age 50: defining risks for mother and child. Am J Perinat 2012, 29:245-250.

73. Le Ray C, Scherier S, Anselem O, Marszalek A, Tsatsaris V, Cabrol D, Goffinet F: Association between oocyte donation and maternal and perinatal outcomes in women aged 43 years and older. Hum Reprod 2012, 27:896-8901.

74. Olivienne F: Avoiding multiple pregnancies. Double trouble: yes as pregnancy is an adverse outcome. Hum Reprod 2000, 15:1663-1665.

75. Land JA, Evers JL: Risks and complications in assisted reproduction techniques: report of an ESHRE consensus meeting. Hum Reprod 2003 18:455-457.

76. Kulkarni AD, Jamieson DJ, Jones HW Jr, Kissin DM, Gallo MF, Macaluso M Adashi EY: Fertility treatments and multiple births in the United States. N Engl J Med 2013, 369:2218-2225.

77. Gleicher N: The irrational attraction of elective single-embryo transfer (eSET). Hum Reprod 2013, 28:294-297.

78. Scotland GS, MvNamee P, Peddle VL, Bhattacharya S: Safety versus success in elective single embryo transfer: women's preference for outcomes of in vitro fertilization. BJOG 2007, 114:977-983.

79. Kita K, Watanabe T, Ohsaka K, Hayashi H, Kubota Y, Nagashima A, Aoki I, Taniguchi H, Noce T, Inoue K, Miki H, Ogonuki N, Tanaka H, Ogura A, Ogawa T: Production of functional spermatids from mouse germline stem cells in ectopically reconstituted seminiferous tubules. Biol Reprod 2007, 76:211-217.

80. White YA, Woods DC, Takai Y, Ishihara O, Seki H, Tilly JL: Oocyte formation by mitotically active germ cells purified from ovaries of reproductive-age women. Nat Med 2012, 18:413-421

81. Hayashi K, Ohta H, Kurimoto K, Aramaki S, Saitou M: Reconstitution of the mouse germ cell specification pathway in culture by pluripotent stem cells. Cell 2011, 146:519-532.

82. Hayashi K, Ogushi S, Kurimoto K, Shimamoto S, Ohta H, Saitou M: Offspring from oocyte derived from in vitro primordial germ cell-like cells in mice. Science 2012, 338:971-975.

doi:10.1186/1477-7827-12-63

Cite this article as: Gleicher et al.: The "graying" of infertility services: an impending revolution nobody is ready for. Reproductive Biology and Endocrinology 2014 12:63.

\section{Submit your next manuscript to BioMed Central and take full advantage of:}

- Convenient online submission

- Thorough peer review

- No space constraints or color figure charges

- Immediate publication on acceptance

- Inclusion in PubMed, CAS, Scopus and Google Scholar

- Research which is freely available for redistribution 